\title{
Refugee Children in the Educational Process: An Social Psychological Assessment
}

\author{
Betül Dilara ŞEKER*
}

\author{
Zafer ASLAN ${ }^{* *}$
}

Received: 08 October 2013
Accepted: 01 October 2014

\begin{abstract}
In this article, the education of refugees' children, discussed as the problems faced by the educational process. With this study, refugee children status, their educational needs, by drawing attention to their problems, to raise awareness about the importance of this issue and is currently non-existent national work, which aims to contribute to a small number. In this review Turkey in the concept of a refugee, refugee children's life in training, the problems encountered in this process will be evaluated and the process of education with social psychological concepts will be discussed and suggestions will be presented on the subject.
\end{abstract}

Keywords: refugee children, education, intergroup relations, education problems

\section{Extended Abstract}

Purpose and Significance: In this study our aim is to clarify education and schooling of refugee children the importance of life will be assessed. Problems experienced by children in this process, the training process will be investigated by social psychological perspective. In this article, the education of refugees children's, in the light of the literature discussed the problems such as socio-cultural difficulties, language, education which they come across in their recent habitats faced by the educational process. In addition purpose of this study the relationships between the groups in the school environment, relationships, categorizing, stereotyping, discrimination and other social psychological concepts to evaluate it.

According to the United Nations Office of the High Commissioner for Refugees 2012 statistics, there are 32.672 refugees in Turkey where according to the police's statistics the number is 36.365 . Either the refugees may have an intervening period/interim period longing for years because of the legal issues/reasons, or during settling to a third country, their accommodation, health care, education, economic, and social needs are covered by the (target ) country (which may be the government, civil society or/and the public). Still, the number of the origin countries may change where $90 \%$ of the refugees live in Turkey are Iraqi, Iranian, Afghan, and Somalian. Although the immigration is perceived to be a subject dealing with adults, apart from these, the needs of children and young immigrants like social, cultural, economic, psychological, and educational issues should be taken into consideration.

Among the refugees in Turkey, 14\% (4538 people) are 5-11 years, and $13 \%$ (4205 people) are 12-17 years children and adolescents. In that case of the refugees living in

\footnotetext{
* Corresponding Author: Assist. Prof. Dr., Celal Bayar University, Manisa, Turkey, dilaraseker@ hotmail.com

MA Student, Celal Bayar University, Manisa, Turkey, zaferaslan65@gmail.com
} 
Turkey, since they are not accepted by a third country for a long time, or even it is not possible to send some of these people to any other country, these groups' education is one concern, which some emphasis should be put on.

Despite of the fact that the school environment is secure and stable in the new society, those children pay an extra effort to adapt to there and their recent peers, for they have experienced a sudden and hard migration period, with their different backgrounds, cultural characteristics, motivations, and they can't share the same language, either. Those children's needs during their education periods should be set forth soon after they are identified, and should be met by the educational institutes and their teachers. To a refugee child, school stands for a safe place against disorder, uncertainty, and chaos; it reminds of the stable and habitual/accustomed life, and it diminishes the traumatic effects, it enables his adaptation to the society, turning him from 'a foreigner' into 'a familiar student'; furthermore, the school meets his needs like belonging to a social group, and it enables him to look at future hopefully.

Schools, since they are places where a variety of groups interacts, support the refugee students also in the adaptation period, and they are effective institutions to lessen the effects of prejudice. Whether willingly or not, refugee children also being members of the society they exist, like the other children in the country, should be placed in the educational institute and the school system, and their needs should be met, furthermore, they should be trained for future. Refugee children and teenagers are individuals who witnessed and were exposed to physical harassment, violence, misery, chaos, and war experiences with difficulties in meeting their basic needs, and who unwillingly had to migrate. In addition to the loses in their countries, and their violence and torture experience, the potential traumatic incidents and unpleasant experiences which they are likely to have during immigration process, and in the target country, effect the immigrant children's physical, social, emotional, and cognitive developmental periods negatively.

The child immigrants, not only because of the war conditions in their countries (like conflicts, chaos, immigration, fleeing), but also because of the physical and social problems they've faced in their recent(target) countries ( they don't know how to get education in that target country, because of some certain circumstances like, the place they are going to settle is not certain yet, lack of language capability, not being able to stay at a certain place for a long time, poor economic conditions, and health problems), find it very difficult to reach the educational facilities. Even, some children may not be able to adapt the education system of either countries (home and target countries). It is commonly observed that refugee children, also, have post trauma stress disorders, depression, and anxiety resulting from former their experiences. Their experience in the process of resettlement of refugee children, their family may have to tackle of the problems arising from the educational environment.

Once the literature about refugee students is studied, the primary problem from which those students have to suffer during their education periods is their parents' attitudes and thoughts towards education. In those studies, it was observed that even though the 
families showed trust for education, and they tolerated it, because of their insufficient economic situations and lack of the target language, they couldn't support their children; besides, this affected their academic success negatively. Education of refugee children in the attitude and willingness of the family have an impact on education but also not rectify the problems. The studies state that though teachers-educators are considered to be among the significant people in an individual's life since they have a role on making those students successful, and understanding life by teaching both the parents and their child the culture. However, sometimes the immigrant students have said that they had problems such as, they were discriminated by their teachers' attitudes, manners, speeches, for they had different cultural backgrounds. To integrate language competence in a new social environment/community is a fundamental necessity. Since there are quite a few studies conducted on refugee's language competence and their motivation level, we have a very limited knowledge about this issue. Studies have found that those factors like refugee adults'/students' traumatic past experiences, their waiting periods at admission centers, their presence at orientation courses, their social integration, their depressions and health problems, or whether they used to live in provinces or in the country have been effective while they were learning the target language.

Methods: Both psychological and educational aspect of refugee children literature reviews. Refugee children's education keywords scanning with published the articles between 2000-2010 was compiled. International literature review was made on Cambridge Journals (CUP), EBSCOhost, Elsevier Science Direct, JSTOR Journals, Oxford Journals (OUP), SAGE Journals Online, Taylor \& Francis Journals, Wiley Online Library search engines, Yuzuncu Y1l University remote access system also used for search process. Due to the limited number of studies focusing on the education of refugee children reached the assembly and empirical articles were examined.

Results: Today, there many groups interacting in diverse environments because of the multi-cultural structure of the communities. Refugees are one of these groups; besides, they are both different from the other groups and the community at large due to their cultural, economic and language dissimilarities. Especially, between these groups, there is a lot needed to increase the amount of the interaction (of both groups) to strengthen their relationships in the education environment. In our everyday life, whether consciously or not, we classify events, people, and situations. This classification brings the term 'foreigner / the other' together. Social identity theory and its adapted form our day 'self-categorizing theory' is vital to explain the relations between groups in our social lives.

There are stereotypes, and -either a wide, or a small group in the society acceptsprejudices, which have been categorized for a certain group, and these. Since the refugee students first considered as members of the groups they belong to, it might cause several problems like alienation, discrimination, or otherization in their 
relationships at school and in class. Similarly, in everyday situations, a student, when in school or class environment, is considered as a(n) 'friend/enemy' due to his/her 'adaptation' capabilities.

Likewise, in Integrated Threat Theory to explain inter group relationships, the out-group member is perceived in four different types such as real threat, symbolic threat, and negative stereotypes, inter group anxiety. This threat perception is affected by interaction, status differences, personal and situational facts (like having close relationships). While in a real threat case, out-group member is perceived as a threat depending on source consuming, in the symbolic threat case, among the home group, because of their life philosophy, different values and beliefs, they are perceived as a threat. Negative stereotypes are threats, which cause prejudice, and direct the expectations towards the out-group. During group intercourses, individuals might have a feeling of being rejected, or may feel anxious/nervous; people are likely to mock at those individuals or their groups; they might be humiliated by being discriminated openly or covertly. They may be exposed to harassment, as well. Throughout group intercourses, refugee students coming from different cultures get used to each other by interacting in the environments like schools, classrooms of which rules have been stated before, and it is believed that this provides a decrease for discomfort felt for the outer group.

According to the social superiority theory, which states that societies never interact equally during group intercourses, social inequality is a stable condition for all the societies. It also states that even every society has beliefs and speeches either supporting inequality or trying to solve the problem, every group hierarchically tends to consider being prior to others. Which of these discourses will be effective is bound to the integration of religion and ideology in the society, and their discourse. In this new environment, all the relationships in the group intercourses, terms like 'foreigner/stranger', stereotype, and prejudice should be understood during the socializing process, and they should be used to clarify the events taking part in everyday life and to solve the problems.

Discussion and Conclusions: Schools are generally a basic contact point for the refugee families and host country, and they lead all the stakeholders; they provide solutions to the problems they come across; they help new comer students to explore ways where they will be able to understand social norms, traditions, to understand each other, how to adapt to the new environment, and how their new world has been established. Like all the children, refugee children have the similar personal requests, which are universal. However, while having their education, it shouldn't be overlooked that they are sensitive groups who have experienced or are already experiencing poor health conditions, anxiety, mistrust, excessive arousal, focusing problems, posttraumatic stress disorders. For that reason, it essential for the refugee children's cognitive, emotional, and social development periods that their teacher provide them social support, and if needed they should be also sent to some specialists. For a refugee 
student to correlate a relationship between school and his socio-cultural adaption, a teacher is very important. That's why the teachers should be considerate about what they are saying at the micro level, and they should be sensitive to students' verbal or nonverbal behaviors. Teachers can create a multi-cultural classroom environment where students are open to learn, where there is no prejudice or discrimination by getting in contact with the family, and learning about their cultures, previous life, by being more aware of their feelings. It is thought it will help the teachers to create a better communication, and this will make it easier to communicate with the parents if they can start with suggesting the points that the students are good at / or may succeed rather than reporting those children's negative behaviors who had many traumas before. For the socio-cultural and academic adaptation of the refugee children, it is important to study with both the mangers and the teachers who are dealing with these groups, and with the refugee children and their families focusing on the process of their relationships. This is, too, significant for increasing a better life for all groups with a higher quality. 


\section{Eğitim Sürecinde Mülteci Çocuklar: Sosyal Psikolojik Bir Değerlendirme}

\author{
Betül Dilara ŞEKER*
}

\author{
Zafer ASLAN ${ }^{* *}$
}

Makale Gönderme Tarihi: 08 Ekim 2013

Makale Kabul Tarihi: 01 Ekim 2014

ÖZET: Bu makalede mülteci çocukların eğitimi, eğitim sürecinde yaşadıkları sorunlar tartışılmaktadır. Bu çalışma ile mülteci çocukların durumlarına, eğitim ihtiyaçlarına, yaşadıkları sorunlara dikkat çekilerek, bu konunun önemi hakkında farkındalık yaratılması ve şu anda yok denecek kadar az sayıda olan yerli çalışmalara katkı sağlanması amaçlanmaktadır. Bu derleme çalışmasında Türkiye'de mültecilik kavramı, mülteci çocukların yaşamında eğitimin yeri, bu süreçte karşılaştıkları sorunlar değerlendirilecek ve eğitim süreci sosyal psikolojik kavramlarla tartışılacak ve konu ile ilgili öneriler sunulacaktır.

Anahtar sözcükler: mülteci çocuklar, eğitim, gruplar arası ilişkiler, eğitim sorunları

\section{Giriş}

Göç süreci toplumların homojen yapısını dönüştürmekte ve toplum içinde göçmenler, konuklar, yabancı öğrenciler, mülteciler gibi farklı grupların ihtiyaç ve sorunlarını gündeme getirmektedir. Mülteci, kendi ülkesinde yaşadığı eziyetten, siyasi veya dini istismardan kaçmak için yaşadığ 1 yerden zorunlu olarak ayrılan ve geri dönme olasılığı bulunmayan kişilerdir (Dalhouse ve Dalhouse, 2009; Roxas, 2010). Toplumdaki diğer gruplarla karşılaştırıldığında mülteciler sosyal belirsizlik, sosyoekonomik zorluklar, yaşanan travmatik olaylar nedeniyle geleceğe dönük planlarını gerçekleştirmek için daha az şansa sahiptirler (Hodes, 2000). Bu nedenle bulundukları toplumda kalıcı bir hayat için gerekli beceri ve yeterliliklerin kazandırılması sürecinde daha fazla desteğe ihtiyaç duyarlar.

Dünyada 2007 yılında 42 milyon yerinden edilmiş kişi bulunmaktadır. Yerinden edilmişlerin, 15 milyonunu mülteci, 827 bini ise şartlı mültecidir (geçici sığınmacı). Yerinden edilmişlerin \%44' ünü 18 yaşın altındaki çocuklar oluşturmaktadır (yaklaşık 7 milyon çocuk) (UNHCR, 2007). Günümüzde yaşanan savaş, çatışma, karmaşıklık, dini, siyasi olumsuzluklar gibi ekonomik krizler, çevresel felaketlerde dünyadaki yerinden edilmiş kişi sayılarının artmasına neden olmaktadır (Betts ve Kaytaz, 2009). Mülteci gruplar hem toplumda görünür olmadıkları, hem de bulundukları ülkede uzun süreli kalacak kişiler olarak düşünülmedikleri için daha az dikkate alınmaktadırlar. Ancak üçüncü ülke kabulünde yeterli şartları sağlayamayan şartlı mültecilerin ülkede kalış süreleri uzamakta, bu süreçte kendileri, aile üyeleri, toplum ve kurumlar ile isteseler de istemeseler de etkileşime geçmektedirler. Özellikle komşu ülkelerde yaşanan kriz durumları ve uzun süreli belirsizlikler, Türkiye'nin bulunduğu coğrafyada cazibesini arttırması, ülkeye gelen yabancı sayısında da artışa neden olmaktadır. Toplumun ülkedeki yabancı nüfusa bakış açısına göre; göç ile birtakım zenginlikler, bazı sorunlar, aynı zamanda insan hakları bağlamında bazı sorumluluklar da ortaya çıkmaktadır.

\footnotetext{
*Sorumlu Yazar: Yrd. Doç. Dr., Celal Bayar Üniversitesi, Manisa, dilaraseker@hotmail.com

***üksek Lisans Öğrencisi, Celal Bayar Üniversitesi, Manisa, zaferaslan65@gmail.com
} 
Mülteciler yeni geldikleri toplumda günlük yaşamdaki değişimlere bağlı birçok zorlukla karşılaşarak, uyum sağlamak için mücadele etmek durumunda kalırlar (Birman, 2002). Yetişkin mülteciler yeni geldikleri toplumda kendileri ile aynı kökene sahip bireylerle bir arada yaşayarak, kendileri için güvenli ve tanıdık bir çevre oluşturabilirler. Ancak bu ailelerin çocukları açısından düşünüldüğünde yaşanan zorluklar daha da artmaktadır. Mülteci çocuk için yeni geldiği toplumda okul çevresi, durağan ve güvenli bir ortam sunmasına rağmen bu çocuklar yaşadıkları ani ve zorlu göç süreçleri, farklı geçmiş ve kültürel özelliklere sahip olmaları, ortak bir dili paylaşmamaları gibi nedenlerle okula uyum sağlamak için ek çaba gösterirler (Hart, 2009; Rutter, 2003). Benzer şekilde okullarda farklı etnik kökenlere sahip kişilerin eğitim ihtiyaçlarına cevap vermek zorunda kalırlar (Pinson ve Arnot, 2010). Bu öğrencilerin eğitim sürecindeki ihtiyaçlarının tanımlanarak ortaya konulması ve ihtiyaçlarının eğitim kurumları, öğretmenler tarafından karşılanmaya çalışılması gerekir. Mülteci çocukların ve gençlerin kurumlar arası işbirliği ile mevcut fırsatlarından yararlanmaları sağlanmalı, güvenilir bir ortamda fiziksel, bilişsel ve psikolojik iyi olmalarını amaç edinen uygun öğrenme ortamlarıyla ilgili düzenlemeler yapılmalıdır (Kirk ve Cassity, 2007).

Günümüzde Türkiye bir geçiş ülkesi olmanın yanında ayrıca coğrafi konumu ile bağlantılı olarak hedef ülke durumuna da gelmiştir. Türkiye'ye yönelik farklı nedenlerle farklı zamanlarda kitlesel göç dalgaları yaşanmaktadır. Bu kitlelerin içinde aileleri ile birlikte veya tek başlarına gelen çocukların da göç ettiği tahmin edilebilir (IOM, 2012). Türkiye'de mültecilerin güvenlik bakış açısı ile zorunlu ikamete tabi tutulduğu belirli sayıda uydu kent olmasına rağmen mültecilerin daha fazla şehre dağılmış durumda olduğu bilinmektedir (Kara ve Korkut, 2010). Mülteci çocukların hangi nedenlerle, ne zaman ve kimlerin refakatinde geldiği konularından bağımsız olarak karşılanması gereken temel ihtiyaçları bulunmaktadır. Bu ihtiyaçların başında da eğitim ihtiyacı gelmektedir. Çalışmanın amacı zorlu ve travmatik bir süreç olan göç sonrasında mülteci çocukların en temel ihtiyaçlarından biri olarak ifade edilen eğitim ihtiyacına dikkat çekmektir. $\mathrm{Bu}$ nedenle çalışmada mülteci çocukların yaşamında eğitimin ve okullaşmanın önemi değerlendirilerek; çocukların bu süreçte yaşadıkları sorunlar sosyal psikolojik bir bakış açısı ile değerlendirilerek incelenmiştir. Aynı zamanda çalışmada konu ile ilgili geleceğe yönelik öneriler de sunulacaktır.

\section{Yöntem}

Çalışma mülteci çocuklar ile ilgili psikoloji ve eğitim bilimleri yazın alanından derlenen çalışmaları ele almıştır. Mülteci çocuk, eğitim, anahtar kelimesi ile tarama yapılmış ve konu ile ilgili 2000-2010 yılları arasında yayınlanan makaleler ele alınarak derlenmiştir. Konu ile ilgili Türkiye'de yapılmış çalışmanın olmadığg görülmüştür. Yurt dışı yazın taraması, Cambridge Journals (CUP), EBSCOHost, Elsevier Science Direct, JSTOR Journals, Oxford Journals (OUP), SAGE Journals Online, Taylor \& Francis Journals, Wiley Online Library arama motorları Yüzüncü Yıl Üniversitesi uzaktan erişim yolu ile tarama yapılmıştır. Yapılan tarama sonucunda mülteci çocukların kendileri, aileleri ve/veya öğretmenleri ile yapılmış farklı çalışmalar olduğu 
görülmüştür. Çalışma sayısı sınırlılığı nedeniyle mülteci çocukların eğitim sorunlarına odaklanan ulaşılan derleme ve görgül makaleler incelenmiştir.

\section{Türkiye'de Mültecilik Kavramının Değerlendirilmesi}

Kamuoyunda yeterince farkındalık oluşmamış olmasına rağmen ülkemize doğru yaşanan göç süreci kendi içinde farklı boyutları ve sorunları barındırmaktadır. Komşu ülkelerde yaşanan karmaşıklıklar dikkate alındığında mülteci sorunun uzun bir süre daha gündemimizde olacağı düşünülmektedir. Üçüncü ülkeye yerleştirilme sürecinde bazı sorunlar yaşayan şartlı mülteciler yıllarca sürebilen bir ara dönem yaşamakta, bu süreçte sosyal, ekonomik, sağlık, eğitim, barınma gibi ihtiyaçlarının bulundukları ülke tarafından (devlet, sivil toplum ve/veya halk tarafından) karşılanması gerekmektedir. Türkiye'de 2001-2010 yılları arasında bulunan mülteciler değerlendirildiğinde; menşe ülke oranları değişmekle birlikte bu grubun İran, Irak, Somali, Afganistan gibi ülkelerden geldikleri saptanmıştır (Ateş, 2011). Mültecilik konusu sadece yetişkinleri ilgilendiren ve kontrol edilmesi gereken bir sorun olarak algılanmasına rağmen yetişkinlerin yanında çocuk ve genç göç edenlerin de sosyal, kültürel, ekonomik, psikolojik, eğitim ihtiyaçları üzerinde de düşünülmesi gerekmektedir (Arnot, Pinson ve Candappa, 2009). Mülteci aileler ve çocuklar sosyal, ekonomik, kültürel olarak homojen algılanmamalıdır. Mülteci grupların farklı özelliklerinin ve ihtiyaçlarının olduğuna dikkat edilmelidir (Rah, Choi ve Nguyen, 2009). Mülteci çocuklarla ilgili alanda yapılan çalışmalar incelendiğinde, bazılarının ikinci dil yeterliliğinin uyum üzerindeki etkiyi değerlendirdiği (örn., Candappa, 2000), bazılarının mülteci çocukların deneyimleri üzerinde durduğu (örn, Pinson ve Arnot, 2007), bazılarının ise çocukların zihinsel ve duygusal sağlıkları ile ilgili olduğu görülmektedir (örn., Anderson, Hamilton, Moore, Loewen, ve Frater-Mathieson, 2004; Szente, Hoot, ve Taylor, 2006).

Türkiye'de 2012 yılı Birleşmiş Milletler Mülteciler Yüksek Komiserliğinin verilerine göre toplam 32.672 kişi bulunurken (UNHCR, 2012); yine aynı yıl polis verilerine göre ise 36.365 kişi (EGM, Yabancılar Hudut İltica Dairesi Başkanlığı verisi) bulunmaktadır. Ancak Türkiye'deki mevcut mülteci sayıları ile ilgili resmi veriler ve bu alanda çalışan ulusal/uluslararası kurumların verileri arasında ciddi farklılıklar bulunduğu gözlenmektedir. Bu durum mülteciler ile ilgili kurum kayıtlarında bir bütünlük bulunmadığının göstergesidir.

Ülkede yaşayan mültecilerin \%90'ını Irakl1, İranlı, Afganlı ve Somalililerden oluşturmaktadır. Mültecilerin \%14'ünü (4538 kişi) 5-11 yaş arası, \%13'ünü ise 12-17 arasında (4205 kişi) çocuk ve ergenlerin oluşturduğu ortaya konmuştur (UNHCR, 2012). Türkiye'deki mülteciler değerlendirildiğinde 5-17 yaş arasında resmi verilere göre toplam 8743 kişi bulunmaktadır. Ancak günümüzde yaşanan göç olayları nedeniyle bu sayının daha fazla olduğu tahmin edilmektedir. Özellikle Türkiye'de yaşayan mültecilerin üçüncü bir ülkeye kabul sürelerinin uzunluğu veya gönderilememe durumları dikkate alındığında üzerinde önemle düşünülmesi gereken konulardan birinin de bu grupların eğitimleri olduğu görülmektedir. Ancak bu grupların eğitime ihtiyac1 olan çocuk ve gençlerle ile ilgili kesin verileri yansıtan ortak bir sistem bulunmamaktadır. Ülkede yaşayan mültecilerin gerçek sayılarının net olarak 
bilinmemesi sadece Türkiye'ye özgü bir durum değildir. Örneğin, İngiltere'de de mülteci çocuk sayıları ve eğitimini sürdüren çocuk sayılarında ulusal istatistiksel verilerde eksiklikler olduğu ifade edilmektedir (Rutter, 2006).

\section{Mülteci Çocukların Yaşamında Eğitimin Yeri}

Mülteci çocuk ve ergenler geldikleri ülkede fiziksel işkence, şiddet, karmaşıklık, savaş durumlarına maruz kalarak temel ihtiyaçlarının karşılanmasında sorunlar yaşayan kendi istekleri dişında göç eden kişilerdir (Harrell-Bond, 2000; Pynoos, Kinzie ve Gordon, 2001; Roxas, 2010). Menşe ülkelerinde yaşanan kayılar, şiddet, eziyet deneyimlerine ek olarak ayrıca göç süreci boyunca ve yeni yerleşilen ülkede de potansiyel travmatik olaylar aileden ayrılma, olumsuz yaşam koşulları, ırkçılık vb. deneyimler de yaşayabilirler. Bütün bu süreçler mülteci çocuk ve ergenlerin gelişimini olumsuz yönde etkileyebilir (Hodes, 2000; Rutter, 2003; Anderson, Hamilton, Moore, Loewen ve Frater-Mathieson, 2004). Benzer şekilde mülteci çocukların yeni geldikleri yerdeki fiziksel ve sosyal sorunlar, yerleşecekleri yerin kesin belli olmaması, uzun süre bir yerde kalmama/kalamama gibi nedenler eğitimlerinde aksamalara neden olabilmekte hatta bazıları ne kendi ülkelerinde ne de geldikleri ülkede eğitim sistemine dahil olamamaktadırlar (Vedder ve Horezcyk, 2006).

Eğitim, çocukların yaşamını yapılandırır, şekillendirir. Eğitim süreci, öğretimi de kapsamaktadır. Öğretimin sistemli ve planlı yapıldığı yer olarak okul bireyin yaşamında önemli bir yere sahiptir. Okullar; düzensizlik, belirsizlik ve karmaşıklığa karşı güvenli, durağan, alışılmış yaşama dönüşü simgeler, çocuktaki mevcut travmatik etkileri azaltır, topluma uyumu kolaylaştırır, çocuk "bir yabancıdan", "diğerlerine benzer bir öğrenciye" dönüşme fırsatı verir, geleceğe umutla bakabilmeyi sağlar (Mosselson, 2006; Sabah, 2007; Keating ve Ellis, 2007; Oikonomidoy, 2010). Okullar, çocukların sosyalleştiği, fiziksel, bilişsel ve sosyal süreçlerinin geliştiği, sosyal kuralların öğrenildiği, özellikle mülteci çocukların topluma dahil olma fırsatı edindiği en önemli kurumlardır (Holloway ve Valentine, 2000; Frater-Mathieson, 2004; Sabah, 2007; Boyden, 2009). Ülkedeki tüm çocukların ve ergenlerin eğitim fırsatlarından yararlanabilmesi için fiziksel, bilişsel, sosyal gelişimleri için uygun ortamlar düzenlenmelidir. Tüm vatandaşlar gibi mülteci çocuklar da eğitim sistemi içine yerleştirilmeli, ihtiyaçları karşılanmalı ve geleceğe hazırlanmalıdır (Roxas, 2010). Okullar topluma uyum sürecinde de mülteci öğrencilere destek olan (Rah, Choi ve Nguyen, 2009), bir gruba ait olma duygusunu etkileyen, önyargıları azaltan kurumlar olarak çocukların yaşamı ve gelecekteki başarılarında önemli bir yere sahiptir (Duncan, 2000; Suarez-Orozco ve Suarez-Orozco, 2001; Boyden, 2009). Mülteci öğrencilerin bulundukları okul çevresi olumlu özelliklere sahip olduğunda, öğrencinin uyumu, aidiyet duygusu ve akademik başarısı artarken, çevrenin olumsuz özellikleri ise öğrencide yabancılaşma duygusu ortaya çıkararak, onu okuldan uzaklaştırmaktadır. Öğrencinin kendini okula ait hissetmesi onun okuldaki deneyimlerine bağlıdır (Phan, 2003; Oikonomidoy, 2010). Okula aidiyet ve bağlılı̆̆ın benlik kavramı, sosyal beceriler, motivasyon ve akademik başarı gibi olumlu akademik, davranışsal, ve psikolojik 
çıtıları bulunduğu; depresyon sosyal-duygusal endişeleri ve sosyal dışlanmaları azalttığı ortaya konulmuştur (Anderman, 2002).

\section{Eğitim Sürecinde Mülteci Çocukların Karşılaştığı Sorunlar}

İnsan yaşamında özellikle mağduriyetler yaşayarak başka bir ülkeye sığınan, destek bekleyen mülteci çocuklarının eğitimi, öğretimi, okullaşması önemli bir konudur. Yapılan çalışmalarda mülteci çocukların eğitim sürecinde ana babaların eğitim sürecini anlamasında ve çocuğu desteklemesinde yaşanan eksiklikler, çocukların dil yetersizlikleri, kendi ülkelerinde hiç eğitim alamamaları veya aldıkları eğitimin eksik olması, okul ortamı, öğretmenlerin/idarecilerin tutum ve davranışlarından kaynaklanan sorunlar yaşadıkları ortaya konulmuştur (Candappa, 2000; Oikonomidoy, 2010; Hek, 2005; Rah, Choi ve Nguyen, 2009; Roxas, 2011).

Fiziksel işkence, şiddet, yoksulluk, yetersiz beslenme, aile ayrımı, yaşayan ve/veya tanık olan mülteci çocuklar sıklıkla pek çok travma deneyimini bir arada yaşadıkları için çoklu dezavantajlı grup olarak değerlendirilir. Yaşanan olumsuz deneyimler çocukların fiziksel, sosyal, duygusal ve bilişsel süreçlerini etkilemektedir. Mülteci öğrencilerin yaşadıkları savaş, karışıklık, göç, kaçma ve geçici yerleşim gibi konular formel eğitim olanaklarına ulaşmalarını engellediği için bu öğrencilerin eksikleri ve/veya farklılıkları bulunmaktadır (Sutner, 2002; Rah, Choi ve Nguyen 2009). Yeniden yerleştirme sürecinde mülteci çocuklar kendi deneyimlerinden, ailelerinden, eğitim ortamından kaynaklanan sorunlarla mücadele etmek zorunda kalabilirler, okula karşı olan iyimserlikleri ve akademik başarı motivasyonları, eğitim sürecinde yaşanan farklı olumsuzluklar nedeniyle etkilenebilir (Suarez-Orozco, 2000). Eğitimin devamlılığında aile, süreci etkileyen en temel unsurlardan biridir. Ailenin eğitimle ilgili tutumu ve istekliliği mülteci çocukların eğitiminde etkili olmakta ancak yaşanan sorunları da gidermemektedir. Mülteci aileler yeni yerleştikleri yerlerde uzun süreler çalışmak zorunda kaldıkları için çocukları ile ilgilenmeye zamanları kalmamasına rağmen çocuklarının iyi derecede dil öğrenmesini, okul ve öğretmenler tarafından desteklemesini istemektedirler. Ancak aileler, dil yetersizlikleri ve okuldan, eğitimden ne bekleyeceklerini bilemedikleri için okuldaki faaliyetlere katılamamaktadırlar (Roxas, 2011). Ayrıca mülteci ailelerin dil ve eğitim yetersizlikleri nedeniyle çocuklarının ödevlerine destek olamadıkları, bu durumdan çocukların akademik başarısının olumsuz etkilediği gözlenmektedir (Rah, Choi ve Nguyen, 2009).

Yapılan farklı çalışmalarda mülteci çocukların okul ortamındaki uyumlarının zor olduğu, dil ve kültürel farklılıklar nedeniyle ayrımcılık gibi sorunlar yaşadıkları ortaya konulmuştur (Kirova, 2001; Suarez-Orozco, 2000). Bulundukları ülkede yaşama uyumda da sorunlar yaşamaktadırlar (Suarez-Orozco, 2000), ayrıca öğretmenlerinin, arkadaşlarının ve yerleşik topluluğun tutarsız/değişken davranışları ile de karşı karşıya kalmaktadırlar (Gitlin, Buendia, Crosland ve Doumbia, 2003). Özellikle öğretmenler, mülteci öğrencilerin farklı kültürel kodları öğrenmesinde, değişsiminde, okuma yazma becerilerini kazandırmada, dili öğrenmesinde ve akıcı olarak kullanmasında, topluma hazırlayan birer kültür işçisi olarak can alıcı öneme sahiptir ve ailelerle işbirliği içinde olmalıdır (Exposito ve Favela, 2003; Roessingh, 2006; Birman, Weinstein, Chan ve 
Beehler, 2007). Küçük yaşta göç deneyimi yaşayan mülteci çocuklarla Amerika Birleşik Devletlerinde (ABD) yapılan bir çalışmada mülteci ergenlerin uyumunun öncelikle okul deneyimlerinden etkilendiği ortaya konulmuştur (Mosselson, 2006). ABD'de okula devam eden mülteci çocuk sayısındaki artışa paralel olarak öğretmenlerin sınıflarındaki öğrencilerin ihtiyaçlarını karşılamak ve onları anlamak için daha fazla bilgiye ihtiyaç duydukları da ortaya konulmuştur (Szente, Hoot ve Taylor, 2006).

Mülteci çocukların kendileri geçmiş deneyimlerinden kaynaklanan travma sonrası stres bozukluğu da yaşayabilirler. Örneğin, çalışmalarda mülteci çocuklarda da yetişkinler gibi travma sonrası stres bozukluğu, depresyon ve anksiyetenin yaygın olduğu ortaya konulmuştur (Hart, 2009; Kirk ve Cassity, 2007; Dalhouse ve Dalhouse, 2009; Roxas, 2011). Öğretmenler, bu öğrencilerin travma deneyimlerinin eğitim yaşamlarında etkili ve önemli olduğuna dikkat etmelidir ancak bunu öğrenciyi acınacak bir kurban objesine dönüştürme aracı olarak kullanmamalıdırlar (Boyden, 2009). Öğrencinin okul ortamında benlik gelişimi içinde öğretmenin yeri oldukça önemlidir (Roessingh, 2006). Öğretmen sınıfta öğrencilerin sözlü ve sözsüz mesajlarını sürekli değerlendirebilir ve bu yol ile onların gelişimine katkıda bulunur. Mülteci çocuklarla çalışan öğretmenlerin tepkileri bireysel olarak engel oluşturabilir. Öğretmenlerin tepkilerini, söylemlerini ve davranışlarını etkileyen kültürel yapılar bulunmaktadır. Öğretmen kaynak araç gereç materyal eksiklikleri de yaşamaktadır. Mülteci öğrencilerin ihtiyaçlarının nasıl karşılanacağı ile ilgili de sorunlar yaşayabilmektedir (Roxas, 2011).

Mülteci öğrenciler, okulda psikolojik sıkıntıları, dil ve akademik yetersizlikler gibi nedenlerden dolayı kendilerini yalnız hissedebilirler ve okulu bırakabilirler (Patiadino, 2008). Yeni gelinen sosyal ortama/topluma katılım için dil yeterliliği temel bir gerekliliktir. Mültecilerin dil yeterlilikleri, motivasyon düzeyleri konusunda yapılan çalışmaların azlığı nedeniyle bu konudaki bilgimiz oldukça sınırlıdır. Ayrıca, mülteci çocukların dil yeterliliği, gelecekteki iş kariyerleri içinde oldukça önemlidir (Heath, Rothon ve Kipli, 2008) ayrıca sonraki kuşakların uyumu içinde anlamlı bir rol oynamaktadır. Çalışmalar mültecilerin çoğunun yaşadığı travmatik olayların, sağlık problemlerinin, depresyonun dil öğrenme sürecinde etkili olduğunu ortaya koymuştur. Ayrıca kabul merkezlerinde kalma süresi, uyum kursuna devam etme, sosyal katılım, depresyon, sağlık sorunları, ayrıca kendi ülkelerinde kırsal alanda veya kentte yaşamalarının da dil öğrenme üzerinde etkili olduğu ortaya konulmuştur (örn. Carliner, 2000; Chiswickand ve Miller 2007; Dustmann ve Fabri 2003; Hwang ve Xi 2008; van Tubergen ve Kalmijn, 2009).

\section{Mülteci Öğrencilerin Eğitim Sürecinin Sosyal Psikolojik Olarak Değerlendirmesi}

Mülteci öğrencilerin eğitim ve okullaşma süreci sosyal psikolojide gruplar arası ilişkilerin açıklanmasında kullanılan, aidiyet, kalıp yargı, önyargı, ayrımcılık kavramları çerçevesinde ele alınacaktır. Gruplar arası ilişkiler açısından bakıldığında okullarda bulunan farklı grupların ilişkilerinde ayırım olumsuz olarak algılanarak, okullarda dini ve etnik ayırımdan kaçınılmaya çabalanır. Ancak günlük yaşamda çevremizdeki olayları, kişileri, durumları farkında olarak ya da farkında olmadan gruplamaktayız. Bu 
gruplama göç süreci beraberinde yabancı/öteki kavramını beraberinde getirmektedir. Sosyal yaşamda gruplar arası ilişkilerin açıklanmasında kullanılan sosyal kimlik ve sosyal kategorilendirme kuramlarında, kimlik farklı soyutluk ve genellik düzeylerinde sosyal kategorizasyonun bir sonucudur. Kalıp yargılar ve önyargılarda gruplar halindeki kategorilendirmelerden kaynaklanır (Bilgin, 2008). Mülteci öğrencilerin okul ve sınıfta ilişkilerinde öncelikle ait oldukları grupla değerlendirilmeleri, süreç içinde farklı sorunlara neden olabilmektedir. Okulda ve sınıfta yaşanan bu süreçler Bauman'un (1991; akt: Szilassy ve Arendas, 2007) sosyal ilişki kuramında de ele alınır. Bu kuramda yabancı kişiler "arkadaş ve düşman" şeklinde değerlendirilir. Yabancı ile ilişki sosyal bağlamda gerçekleştiği için ve bu ilişkide çatışmaların yaşanması da kaçınılmazdır. Yabancı sergilediği "uyma" yeteneği ile arkadaş veya düşman olarak tanımlanmaktadır. Benzer şekilde gruplar arası ilişkilerde önyargıların açıklanmasında bütünleşmiş tehdit kuramında de dış grup üyesi (yabancı) gerçekçi, sembolik, olumsuz stereotipler ve gruplar arası anksiyete dört farklı şekilde tehdit olarak algılanmaktadır (Stephan, Ybarra, Mart'1nez, Schwarzwald ve Tur-Kaspa, 1998). Bu tehdit algısı; etkileşim, statü farklılıkları, kişisel ve durumsal faktörlerin (yakın ilişki kurma) etkisi ile farklı gruplardan bireylere karşı olan tutum ve davranışları etkilemektedir (Ward, Masgoret ve Gezentsvey, 2009). Gerçekçi tehdit durumunda, dış grup kaynak kullanımına bağlı tehdit olarak algılanmakta iken; sembolik tehdit durumunda iç grup tarafından farklı değerler, inançlar ve değerler tehdit olarak algılanmaktadır. Olumsuz stereotipler, önyargıya neden olan ve dış grupla ilgili beklentileri yönlendiren temsili tehditlerdir. Gruplar arası ilişkilerde kişiler ret edilme korkusu ve kaygı hissedebilirler; kendileri ve grupları ile alay edilebilir, açık veya örtülü ayrımcılığa uğrayarak utandırılabilir ve istismara maruz kalabilirler. Özellikle ülkedeki yabancılara karşı tutumlarda bu dört tehdit algısı üzerinde durulmaktadır. Farklı kültürlerden öğrencilerle yapılan çalışmalarda da ev sahibi öğrencilerin farklı gruplardan öğrencilerle daha az etkileşim içinde oldukları ve farklı gruplar hakkında daha olumsuz stereotipilere sahip oldukları gözlenmiştir (Spencer-Rodgers ve McGoven, 2002). Gruplar arası düşük anksiyeteye sahip öğrencilerin farklı kültürel gruplardan öğrencileri daha olumlu değerlendirdikleri ve daha fazla etkileşime girmeye istekli oldukları (Stephan ve Stephan, 2000) saptanmıştır. Okul uyumu, hem akademik başarıyı hem de sağlıklı kültürlerarası ilişkileri kapsamaktadır. Farklı sosyalleşme alanlarından gelen mülteci öğrenciler ırksal, dini, dilsel ve kültürel kimlikleri ile ilgili olarak örtük veya açık sorunlar yaşamalarının yanında okulda "yeni gelen" olarak da sorunlar yaşarlar (Szilassy ve Arendas, 2007). Toplumsal üstünlük kuramında da toplumsal eşitsizlik toplumların değişmez bir özelliği olduğu ve her toplumda hem eşitsizliğin sürmesine hem de giderilmesine ilişkin inanç ve söylemler bulunduğu ifade edilmektedir (Hortaçsu, 2012; Esses, Dovidio ve Hodson, 2005). Bu söylemlerden hangisinin etkili olacağ 1 söylemle toplumun dini ve ideolojik inançlarıyla bütünleşmesine bağlıdır. Aynı zamanda kalıcı bir kişilik özelliği olarak kendi grubunu hiyerarşik olarak diş gruplardan üstün görme gibi bir toplumsal üstünlük yönelimi de ortaya konur (Esses, Dovidio, Hodson, Jackson ve Armstrong, 1998; Hortaçsu, 2012). Yeni gelinen ortamda sosyalleşme sürecinde gruplar arası ilişkiler, 
yabancı, kimlik, kalıp yargı, önyargı gibi kavramlar süreç içinde anlaşılmalı ve günlük yaşam pratiklerine olumlu uygulamalarla yansıtılmalıdır.

Gruplar arası etkileşim sağlandıkça farklı gruplar birbirini tanıdıkça, bu süreçte önyargılarının azalacağı yapılan çalışmalarla da ortaya konulmuştur. Ancak gruplar arası etkileşim sürecinde gruplar arası eşit statü, gönüllülük, memnuniyet düzeyi, yakın ve işbirlikçi ilişkininde önyargıları azaltmada etkili olduğu ve algılanan tehdit miktarını azalttığ1 gözlenmiştir (Pettigrew ve Trop, 2006; Stephan ve Stephan, 2000). Gruplar arası ilişki sürecinde farklı kültürden gelen mülteci öğrenciler okul ve sınıf gibi kuralları önceden belirlenmiş ortamlarda etkileşime girerek birbirlerini tanırlar ve bu süreçte diş gruba karşı hissedilen kaygı düzeyinde de azalma sağlanabilir.

Bizlerin dünyada nasıl düşünmesi, hissetmesi ve davranması gerektiği; diğerleri ile ilişkiler ve mesajlar sonucu oluşan "kültürel senaryolar"; kamu politikaları, kurum uygulamaları, medya, kitaplar ve diğer mekanizmalar yolu ile belirlenir (Gee, 2000). Bu mekanizmalar kişilerin şemalarını oluşturur; özellikle mülteciler ile ilgili üretilen kültürel şemalar onların algılanma ve onlara karşı davranış şekillerini biçimlendirir. Mülteci ögrenciler ve onların aileleri hakkında da kültürel senaryolar bulunmaktadır. $\mathrm{Bu}$ gruplarla çalışan öğretmenler de geniş bir kültürel çatının üyesidir ve kültürel senaryonun uygulanması sürecinde genel düşüncelerden etkilenmektedirler. Toplum içinde dar veya geniş bir kesimce paylaşılan bir toplumsal gruba ilişkin kalıp yargılar (stereotype) oluşur (Hortoçsu, 2012). Genellikle farklı grupları, azınlıkları, milliyetleri hedef alan, çevredeki uyaranları tasnif ederek basitleştiren, çevreyi düzene sokan, olumsuz yükü önyargılara göre daha az olan kalıp yargılar; bir grubun üyelerinin başka bir grubun veya kendi grubunun tüm üyeleri hakkında paylaştıkları örtük kişilik kuramları gibidir. Aynı zamanda bu kalıp yargılar diğer grupla kurulan ilişkiye göre de zaman içinde değişebilir (Bilgin, 2008; Hortaçsu, 2012). Kalıp yargılar mültecilerin geniş grup içinde kimliğini, diğer grupların onlardan beklentisini, kurulacak ilişki düzeyini de etkileyebileceği düşünülmektedir.

\section{Sonuç ve Tartışma}

Ülke dışından gelen kişi sayısı arttıkça ülkede eğitim, öğretim alanında mülteci çocuklarla ilgili sorunlarla daha sık karşılaşılacağı bir gerçektir. Ülkemizde eğitim alanında var olan sınıfların kalabalık olması, sistemden kaynaklanan farklı sorunların yanında mülteci çocukların özel durumlarından kaynaklanan sorunlarda bulunmaktadır. Okullar genellikle mülteci aileler ve ev sahibi ülke için temel bir irtibat noktasıdır, tüm paydaşlara yol gösterir ve aileler okullarda yeni geldikleri yerde dünyanın nasıl yapılandırıldı̆̆ını, sosyal normları, gelenekleri, nasıl uyum göstereceklerini birbirlerini anlama yönündeki yolları keşfederler (Rah, Choi ve Nguyen, 2009). Bu kurumların çok kültürlü yapıda ortaya çıkabilecek sorunların çözümünde katkı sağlaması tüm paydaşlar için önemlidir.

Mülteci çocuklar, kötü sağlık koşulları, anksiyete, güvensizlik, aşırı uyarılmışlık, odaklanma sorunları, depresyon, travma sonrası stres bozukluğu yaşamış/yaşayan hassas gruplar oldukları eğitim sürecinde göz ardı edilmemelidir. Yaşanan bu olumsuz 
deneyimler çocukların bilişsel süreçlerini olumsuz etkileyebilir. $\mathrm{Bu}$ nedenle mülteci çocuklara öğretmenler tarafından sağlanacak sosyal destek, ihtiyaç duyulduğunda uzmanlara yönlendirilerek alabilecekleri diğer destekler onların gelişim süreçleri açısından önemlidir.

Mülteci öğrencilerin dini, ırksal, dilsel ve kültürel kimlikleri okulda açık veya örtük mücadeleye neden olabileceği, sık rastlanan bir durumdur ve gözden kaçırılmamalıdır. Gruplar arası ilişkilerin sağlıklı gelişmesinde, ayrımcılık ve ırkçılığın önlenmesinde, belirsizlik ve gerilimin azaltılmasında eğitim ortamları ciddi faaliyetleri ile önemli mücadeleler verir. Çok kültürlü eğitim kavramının temeli; farklılıkların ve tüm kültürel grupların eşit saygıya değer olduğunun vurgulanmasına dayanmaktadır. Bu kavramla ilgili okullarda çalışmalar yapılabilir ve öğrencilere birlikte yaşamın önemi anlatılabilir. Ülkede çok kültürlülüğün anlaşılması özellikle sorunların çözümünde hayati önem taşımaktadır. Mülteci çocukların yoğun olarak yaşadığı bölgelerde/ kentlerde yerel bazı farkındalıklar/ hassasiyetler, çözüm arayışları olmasına rağmen merkezi düzeyde farkındalığın yeni yeni oluştuğu gözlenmektedir. Eğitimin farklı kademeler ve kurulma aşamasında olan kabul merkezlerinde uygulanması için farklılıklara saygılı eğitim programları hazırlanması önem taşımaktadır. Ayrıca mülteci öğrencilerin mevcut durumlarını, sorunlarını, ihtiyaçlarını ve bu grup öğrencilerle çalışan öğretmenlerin de sorunlarını ve karşılaştıkları sorunlarda kullandıkları çözüm yollarını ortaya koyacak araştırmalara da ihtiyaç vardır.

Öğretmen, öğrencinin eğitim yaşamında, sosyo-kültürel uyumunda ve okulla bağ kurmasında oldukça önemli bir aktördür. $\mathrm{Bu}$ nedenle öğretmenler sınıfta mikro düzeydeki söylemlerine sürekli dikkat etmeli, öğrencilerin sözel ve sözel olmayan davranışlarına duyarlı olmalıdır. Öğretmen, öğrenci ve eğitim materyali arasında bağ kurarak başarının ve eğitim kalitesinin arttırılmasında da önemli bir role sahiptir. Öğretmenlere çok kültürlü bakış açısı, önyargısız düşünme kazandırılmalıdır. Ayrıca öğretmenlere mülteci çocukların arka planlarının ne olduğuna dair temel bilgiler sağlanmalıdır (Hones, 2002). Öğretmenler mikro düzeyde sınıflarındaki öğrenci gruplarının kültürel özellikleri ile ilgili bilgilendirilmelidir. Öğretmenler, aile ile iletişime geçerek, ailenin kültürel özellikleri, geçmişi gibi konuları öğrenerek, ailenin ve çocuğun duygularının farkında olarak çok kültürlü, önyargısız, ayrımcılığın olmadığı ve gelişime açık bir sınıf oluşturabilirler (McBrien, 2003, 2005; Hek, 2005). Öğretmenlerin velilerle öncelikle çoklu travma yaşayan bu çocukların davranışları ile ilgili olumsuz bilgileri paylaşmadan önce iyi oldukları/ olabilecekleri alanlar olduğu vurgulanarak iletişime başlamalarının iletişimi kolaylaştıracağı düşünülmektedir.

$\mathrm{Bu}$ alanda yapılacak çok kültürlü öğretmen eğitiminin önemli bir role sahip olduğu düşünülmektedir ve özellikle öğretmenlerin bilgisi, tutumları ve becerileri üzerinde durularak bu boyutlarda eğitim planları geliştirilmelidir. Bu üç bileşen genel olarak birbiriyle ilişkili, öğrencilerin psikolojik iyi olma ve sosyo-kültürel uyumları üzerinde etkili olmakta aynı zamanda öğretmenlerinde kişisel ve profesyonel anlamda iyi olmalarına katkı sağlamaktadır (Vedder ve Horenzcyk, 2006). Eğitim verenlere yönelik kurumsal politikaların geliştirilmesi, eğitimin mülteci öğrenciler için başarılı 
olarak yürütülmesi yanında bütünsel eğitim kalitesine de olumlu katk1 sağlayacağ1 düşünülmektedir. Türkiye'de de mülteci çocukların eğitimsel deneyimlerini, eğitim sürecinde öğrencilerin aileleri ile ilişkilerini, ailelerin toplumla ilişkilerini, başarılı göç stratejilerini, dil yeterlilikleri, ihtiyaçları, sorunları ile ilgili, okula aidiyet, topluluk duygusu, psikososyal uyumları, akademik yeterlilikleri ile ilgili çalışmalar yapılmasına ihtiyaç vardır.

Sonuç olarak; mülteci çocukların bireysel istekleri de diğer çocukların isteklerine benzer, evrensel ihtiyaçlardır (Pinson ve Arnot, 2007). Ancak onların hassas durumları nedeniyle öğretmenlerin ve okul çalışanlarının mülteci öğrencilere daha fazla dikkat ve özen göstermesi gerekmektedir. Çünkü bireylerin geçmiş ve şimdiye ait mücadeleleri ancak geleceğe ait umutları varsa sürekli olur (Bennet, 2007; Oikonomidoy, 2010). Özellikle son dönemlerde Suriye'den gelenlerle birlikte yeni gelen öğrencileri anlamak için onların psikolojik, sosyal ve akademik olarak çok boyutlu analiz edilmeleri, ülkede kaldıkları süre boyunca yaşam kalitelerini arttıracağı ve onları geleceğe hazırlayacağı aynı zamanda ortaya çıkabilecek ülke açısından olumsuz sonuçlara engel olabileceği düşünülmektedir.

Ayrıca günümüzde sosyal psikoloji ve eğitim bilimleri alanında yapılacak mülteciler ve yerleşik halk arasındaki çalışmalara daha fazla ihtiyaç duyulmaktadır. Bu konular üzerinde çalışılması gereken ayrıca bir sosyal zorunluluk olarak karşımıza çıkan konulardır (Liebkind, 2004). Bu çalışmaların çıtıtıarı, okulda ve okul dışında her iki alanda etnik gruplar arası ilişkilerdeki belirsizliği ve gerilimi azaltabilecek bilgi, gözlem ve tespitleri ortaya koyarak karar alıcılar ve alanda çalışanlara rehberlik edebileceği öngörülmektedir.

Sosyal üstünlüğün ve olumsuz stereotiplerin en aza indirildiği, çok kültürlü ideoloji içinde çeşitliliğe karşı olumlu tutumlara sahip olma ve sosyal yapı içine eklemlenme önemli kavramlardır. Toplum tarafından farklılıkların paylaşılması ve uyum sürecine katkı sağlaması vurgulanmaktadır (Berry, 2006). Özellikle mülteci çocukların sosyo kültürel ve akademik uyumları için hem öğretmen ve idarecilerle hem de mülteci çocuklar ve aileleri ile aynı zamanda da geniş toplumla ilişkilerini kapsayan çalışmaların yapılması sorunların çözümü ve tüm grupların yaşam kalitesini arttırmaya katkı sağlayacağı düşünülmektedir. 


\section{Kaynakça}

Anderman, E. M. (2002). School effects on psychological outcomes during adolescence. Journal of Educational Psychology, 94(4), 795-809.

Anderson, A., Hamilton, R., Moore, D., Loewen, S. \& Frater-Mathieson, K. (2004). Education of refugee children: Theoretical perspectives and best practice. In R. Hamilton \& D. Moore (Eds.), Educational interventions for refugee children (pp. 1-11). London: Routledge Falmer.

Ateş, S. (2011). Uluslar arası korumanın bileşeni olarak entegrasyon. Iç̧inde Iltitica, Uluslar arası Göç Ve Vatansızlık: Kuram, Gözlem ve Politika (ss: 309-347). Çelebi Ö., Özçürümez S. \& Türkay Ş. (Eds.), Ankara: BMMYK Yayınları.

Arnot, M., Pinson, H. \& Candappa, M. (2009). Compassion, caring and justice: Teachers' strategies to maintain moral integrity in the face of national hostility to the "non-citizen". Education Review, 61(3), 249-264.

Bennett, C. I. (2007). Comprehensive multicultural education: Theory and practice (6th ed.). Boston: Allyn and Bacon.

Berry, J. W. (2006). Mutual attitudes among immigrants and ethnocultural groups in plural societies. International Journal of Intercultural Relations, 30, 719-734.

Betts, A. \& Kaytaz, E. (2009). National and international responses to the Zimbabwean exodus: Implications for the refugee protection regime. New Issues in Refugee Research, Research Paper No. 175. July. UNHCR.

Bilgin, N. (2008). Sosyal Psikoloji. Ege Üniversitesi Edebiyat Fakültesi Yayınları. No: 145. İzmir: Ege Üniversitesi.

Birman, D. (2002). Refugee mental health in the classroom: A guide for the ESL teacher. Denver, CO: Spring Institute for Intercultural Learning. Erişim Tarihi (28.02.2013). http://www.springinstitute.org.

Birman, D., Weinstein, T., Chan, W. Y. \& Beehler, S. (2007). Immigrant youth in U.S. schools: opportunities for prevention. The Prevention Researcher, 14(4), 14-17.

Boyden, J. (2009). What place the politics of compassion in education surrounding noncitizen children?. Education Review, 61(3), 265-276.

Candappa, M. (2000). Building a new life: The role of the school in supporting refugee children. Multicultural Teaching, 19(1), 28-32.

Carliner, G. (2000). The Language ability of U.S. immigrants: Assimilation and cohort effects. International Migration Review, 34(1), 158-82.

Chiswick, B. R. \& Miller P. W. (2007). The Economics of Language: International Analysis. London: Routledge.

Dalhouse, D. W. \& Dalhouse, A. D. (2009). When two elephants fight the grass suffers: Parents and teachers working together to support the literacy development of Sudanese youth. Teaching and Teacher Education, 25, 328-335. 
Duncan, J. (2000). Overview of mental health findings for UAM and separated children interviewed as part of UNHCR best interest determinations. Kakuma Refugee Camp, Kenya: Unpublished Report.

Dustmann, C. \& Fabbri, F. (2003). Language proficiency and labour market performance of immigrants in the UK. The Economic Journal, 113, 695-717.

Esses, V. M., Dovidio J. F. \& Hodson G. (2005). Historical and Modern Perspectives on Group Competition. In Social Psychology of Prejudice: Historical and Contemporary Issues. Crandall C. \& Schaller M. (Eds). Lawrence, KS: Lewinian Press. Pp. 94-114.

Esses, V. M., Dovidio, J. F. Hodson G., Jackson, L. M. \&. Armstrong T. L (1998). Intergroup competition and attitudes toward immigrants and immigration: An instrumental model of group conflict. Journal of Social Issues, 54; 699-724.

Exposito, S. \& Favela, A. (2003). Reflective voices: Valuing immigrant students and teaching with ideological clarity. The Urban Review, 35(1), 73-91.

Frater-Mathieson, K. (2004) Refugee trauma, loss and grief, in: R. H. and D. Moore (Eds.) Educational Interventions for Refugee Children (pp. 12-31). London: Routledge Falmer.

Gee, J. (2000). The new literacy studies: From 'socially situated' to the work of the social. Barton D., Hamilton M. \& Ivanic R. (Eds.), Situated literacies: Reading and writing in context. New York: Routledge.

Gitlin, A., Buendia, E., Crosland, K. \& Doumbia, F. (2003). The production of margin and center: Welcoming-unwelcoming of immigrant students. American Educational Research Journal, 40(1), 91-122.

Harrell-Bond, B. (2000). Are refugee camps good for children? (Working Paper No. 29). Cairo: American University in Cairo, Forced Migration and Refugee Studies.

Hart, R. (2009). Child refugees, trauma and education: interactionist considerations on social and emotional needs and development. Educational Psychology in Practice, 25(4), 351-368.

Heath, A. E, Rothon, C. \& Kipli, E. (2008). The second generation in Western Europe: education, unemployment, and occupational attainment. Annual Review of Sociology, 34, 211 -235.

Hek, R. (2005). The role of education in the settlement of young refugees in the UK: the experiences of young refugees. Practice, 17(3), 157-171.

Hodes, M. (2000). Psychologically distressed children in the United Kingdom. Child Psychology and Psychiatry Review, 5(2), 57-68.

Holloway, S. \& Valentine, G. (2000). Sociology and the new social studies of childhood. Sociology, 34, 770-771.

Hones, D. (2002). American dreams, global visions: Dialogic teacher research with refugee and immigrant families. Mahwah, NJ: Lawrence Erlbaum. 
Hortaçsu, N. (2012). En Güzel Psikoloji Sosyal Psikoloji. Ankara: İmge Kitabevi Yayıncilik.

Hwang, S.S. \& Xi, J. (2008). Structural and individual covariates of English language proficiency. Social Forces, 86(3), 1079-1 104.

Kara, P. \& Korkut, R. (2010). Türkiye'de göç, iltica ve mülteciler. Türk Idare Dergisi, (467), 153-162.

Keating K.M. \& Ellis, B.H. (2007). Belonging and connetion to school in resettlement: Young refugees, school belonging, and psychosocial adjustment. Clinical Child Psychology and Psychiatry, 12(1), 29-43.

Kirk, J. \& Cassity, E. (2007). Minimum standards for quality education for refugee youth. Youth Studies Australia, 26, 50-56.

Kirova, A. (2001). Loneliness in immigrant children: Implications for classroom practice. Childhood Education, 77, 260-267.

Liebkind, K. (2004). Group size, group status and dimensions of contact as predictors of intergroup attitudes. Group Processes and Intergroup Relations, 7, 145-159.

McBrien, J. L. (2003). A second chance for refugee students. Educational Leadership, 61(2), 76-79.

McBrien, J. L. (2005). Educational needs and barriers for refugee students in the United States: A review of the literature. Review of Educational Research, 75(3), 329-364.

Mosselson, J. (2006). Roots \& routes: A re-imagining of refugee identity constructions and the implications for schooling. Current Issues in Comparative Education, 9(1), 20-29.

Oikonomidoy, E. (2010). Zooming into the school narratives of refugee students. Multicultural Perspective, 12(2),74-80.

IOM, (2012) Topcuoğlu, R. A. Türkiye’de Göçmen Çocukların Profili, Sosyal Politika ve Sosyal Hizmet Önerileri Hızlı Değerlendirme Araştırması, Ankara.

Patiadino J. M. (2008). Identifying a theoretical perspective to meet the educational needs of twice-migrated sudanese refugees. Journal of Ethnographic \& Qualitative Research, 2, 197-204.

Pettigrew, T. F. \& Tropp, L. (2006). A meta-analytic test of intergroup contact theory. Journal of Personality and Social Psychology, 90, 751-783.

Pinson H. \& M. Arnot (2007). Sociology of education and the wasteland of refugee education research, review essay. BJSE, 28: 3, 399-407.

Phan, T. (2003). Life in school: Narratives of resiliency among Vietnamese-Canadian youths. Adolescence, 38(151), 555-566.

Pinson, H. \& Arnot, M. (2010). Local conseptualisation of the education of asylumseeking and refugee students: from hostile to holistic models. International Journal of Inclusive Education, 14(3), 247-267.

Pynoos, R.S. Kinzie, J.D. \& Gordon, M. (2001). Children, adolescents, and families exposed to torture and related trauma. In E. Gerrity,T.M. Keane,\& F. Tuma (Eds.), 
The mental health consequences of torture (pp. 211-225). New York: Kluwer Academic/Plenum Publishers.

Rah, Y. Choi,S. \& Nguyen, T.S.T. (2009). Building bridges between refugee parents and schools. International Journal of Leadership in Educational, 12 (4), 347-365.

Roessingh, H. (2006). The teacher is the key: Building trust in ESL high school programs. The Canadian Modern Language Review, 62(4), 563-590.

Roxas, K. (2010). Who really wants "the tired, the poor, and the huddled masses" anyway?: Teachers' use of cultural scripts with refugee students in public schools. Multicultural Perspectives, 12(2), 65-73.

Roxas, K. (2011). Tales from the front line: Teachers' responses to Somali Bantu refugee students. Urban Education, 46(3), 513-548.

Rutter, J. (2003). Supporting refugee children in 21 st century Britain: A compendium of essential information. Stoke on Trent: Trentham Books.

Rutter, J. (2006). Refugee children in the UK. Maidenhead: Open University Press.

Sabah, C. (2007). Social adjustment and idealized identity of refugee adolescents. International Journal of The Humanities, 4(7), 117-124.

Stephan,W. G., Ybarra, O., Mart' ınez, C., Schwarzwald, J., \& Tur-Kaspa,M. (1998). Prejudice towards immigrants to Spain and Israel: An integrated threat theory analysis. Journal of Cross-Cultural Psychology, 29, 559-576.

Stephan, W. G. \& Stephan, C. W. (2000). An integrated theory of prejudice. In S. Oskamp (Ed.), Reducing Prejudice and Discrimination: The Claremont Symposium on Applied Social Psychology (pp. 23-45). Mahwah, NJ: Lawrence Erlbaum.

Spencer-Rodgers, J. \& McGovern, T. (2002). Attitudes toward the culturally different: The role of intercultural communication barrier, affective responses, consensual stereotypes and perceived threat. International Journal of Intercultural Relations, 26, 609-631.

Suarez-Orozco, C. (2000). Identities under siege: Immigration stress and social mirroring among the children of immigrants. In A. Robben \& M. Suarez-Orozco (Eds.), Cultures under siege: Collective violence and trauma (pp. 194-226). New York: Cambridge University Press.

Suarez-Orozco, C. \& Suarez-Orozco, M.M. (2001). Children of immigration. Cambridge, MA: Harvard University Press.

Sutner, S. (2002) How schools can help refugee students. Harvard Education Letter, $18(5), 3-5$.

Szente, J., Hoot, J. \& Taylor, D. (2006). Responding to the special needs of refugee children: practical ideas for teachers. Early Childhood Education Journal, 34(1), $15-20$.

Szilassy, E., \& Arendas, Z. (2007). Understandings of difference in the speech of teachers dealing with refugee children in Hungary. Journal of Ethnic and Migration Studies, 33(3), 397-418. 
Office of the United Nations High Commissioner for Refugees. (2007). 2006 Global Trends: Refugees, Asylum-seekers, Returnees, Internally Displaced Persons and Stateless Persons. UNHCR.

Office of the United Nations High Commissioner for Refugees Statistics, (2012) UNHCR Turkey's Monthly Statistics. Erişim Tarihi:04.03.2013. http://www.unhcr.org.tr/uploads/root/statistical_tables_new_format_tr\%281\%29.pd f.

Van Tubergen, F., \& Kalmijn, M. (2009). Language use and proficiency of immigrants in the Netherlands: Opportunities or Incentives?. European Sociological Review, 25(2), 169-82.

Vedder, P., \& Horenzcyk, G. (2006). Acculturation and the school context. In D. L. Sam, \& J. W. Berry (Eds.), Psychology of acculturation; international perspectives (419-438). Cambridge: Cambridge University Press.

Ward C, Masgoret, A.M. and Gezentsvey M. (2009). Investigating attitudes toward international students: Program and policy implications for social integration and international education. Social Issues and Policy Review, 3(1), 79-102. 